\title{
PODCAST
}

\section{First Rounders: Ted Love}

Ted Love is the president and CEO of Global Blood Therapeutics. In his conversation with Nature

Biotechnology, he discusses why his time at Haverford College was transformative, why he views Global Blood Therapeutics as a social justice company, and what might be gained from the "racial catharsis" happening in America after the police killing of George Floyd.

https://aca.st/55237e

\section{PODCAST}

\section{Forum: CRISPR roundtable with Doudna and Liu}

Jennifer Doudna and David Liu talk with Senior Editor Markus Elsner about the state of the genome-editing field and what challenges remain, especially as various therapies are now entering the clinic.

https://aca.st/70c758

Published online: 14 July 2020

https://doi.org/10.1038/s41587-020-0619-8

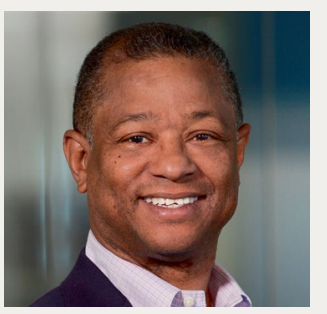

\section{RESEARCH HIGHLIGHTS}

\section{Papers from the literature}

Selected by the Nature Biotechnology editors.

CRISPR-Cas $\Phi$ from huge phages is a hypercompact genome editor Pausch, P. et al. Science https://doi.org/10.1126/science.abb1400 (2020).

Neutralizing nanobodies bind SARS-CoV-2 spike RBD and block interaction with ACE2

Huo, J. et al. Nat. Struct. Mol. Biol. https://doi.org/10.1038/s41594-020-0469-6 (2020).

A bacterial cytidine deaminase toxin enables CRISPR-free mitochondrial base editing

Mok, B. Y. et al. Nature https://doi.org/10.1038/s41586-020-2477-4 (2020).

Next-generation sequencing of $\mathrm{T}$ and $\mathrm{B}$ cell receptor repertoires from COVID-19 patients showed signatures associated with severity of disease

Schultheiß, C. et al. Immunity https://doi.org/10.1016/j.immuni.2020.06.024 (2020).

Origins and proliferative states of human oligodendrocyte precursor cells

Huang, W. et al. Cell https://doi.org/10.1016/j.cell.2020.06.027 (2020). 